\title{
Kriging Infill of Missing Data and Temporal Analysis of Rainfall in North Central Region of Bangladesh
}

\author{
Nazia Hassan Choudhury*, Ataur Rahman and Sara Ferdousi
}

Department of Water Resources Engineering, Bangladesh University of Engineering and Technology, Dhaka-1000, Bangladesh

\begin{abstract}
The north-central region of Bangladesh is subjected to rapid land use pattern changes as a result of continuous unplanned urbanization, encroachment of water bodies and agricultural land, filling up of designated wet lands and flood flow zones by real estate companies. There is a growing need to consider rainfall regimes an important factor in assessing drainage network design, flood control work, soil and water conservation planning, watershed management and likes. The historic data of daily rainfall of 7 climate stations in the area comprising 4 districts of Dhaka (Banani, Savar and Dhaka_PBO), Narayanganj (Shimrail), Narsingdi (Narsingdi) and Gazipur (Joydebpur and Maona), 4 of which are for 30 years (1984-2013), 1 is for 21 years (1993-2013) and 2 are for 18 years (1996-2013). An assessment of Kriging infill is conducted and appreciable results confirmed for a missing station from moderate values of nearby observed rainfall. The missing volume of data is identified as $7.95 \%$ and infilled by Geostatistical approach Kriging in Arc-GIS 10.1. The Kriging generated data and the observed set of data are both then analyzed station-wise for temporal variation on yearly, monthly and seasonal basis. Kriging yields most significant results for monsoon and pre-monsoon seasons. Localized trends are observed at all stations. Kriging Average Annual Rainfall (AAR) and total rainfall values are higher than observed ones; highest AAR of $2047 \mathrm{~mm}$ at Dhaka PBO and lowest $1322 \mathrm{~mm}$ at Joydebpur; the highest monsoon rainfall of $1343 \mathrm{~mm}$ is at Maona, the highest pre-monsoon rainfall of $465 \mathrm{~mm}$ is at Dhaka_PBO and the highest post-monsoon rainfall of $208 \mathrm{~mm}$ is at Shimrail.
\end{abstract}

Keywords: Multi-temporal analysis; Geostatistics; Infill method; Kriging

\section{Background}

\section{Introduction}

Bangladesh receives some of the heaviest rainfall in the world [1]. Annual Average rainfall in Bangladesh ranges from a low of $1,200 \mathrm{~mm}$ in the west to almost $6,000 \mathrm{~mm}$ in the east where huge uplifting effects of Meghalaya Plateau compose the highest rainfalls of the world just beyond the border with India [2]. IPCC has termed Bangladesh as one of the most vulnerable countries in the world due to climate change. Hydrological changes are the most significant impacts of climate change in Bangladesh and resultant altered precipitation patterns cause frequent extreme weather events, such as floods, droughts and rainstorms etc., [3-5].

The variability of rainfall and pattern of extreme high or low precipitation are important for the agriculture and hence economy of the country. The study of rainfall patterns and intensities of heavy rainfall events which constitute the hydrologic design and analysis is the primary prioritized requirement in design of development works and study of impact assessments alike.

The variation of rainfall over an area can be studied on spatial or temporal basis. The several spatial variation approaches are by station, basin, sub-basin, watershed, etc.,

Temporal studies can be short term basis or long term basis. Short term variations are concerned with intensities of rainfall and are obtained either from recorded short interval data or from daily data by the application of empirical formulae in 15 minutes, 30 minutes, hourly or three-hourly intervals. Long term variations are usually based on climate normals and are further studied on yearly, monthly or seasonal basis. Four distinct seasons can be recognized in Bangladesh from the climatic point of view:

i. Dry Winter season (December, January, February; DJF). ii. Pre-monsoon Hot Summer season (March, April, May; MAM).

iii. Rainy Monsoon season (June, July, August, September; JJAS).

iv. Post-monsoon Autumn season (October, November; ON).

\section{Objectives}

The study attempts to initially infill the missing daily data within the observed data set to generate a Kriging set of data and then proceed analysis with both sets of data alike. The key objectives are:

i. Assessment of Kriging infill.

ii. Infilling missing daily data of 7 climate stations by Kriging.

iii. Station-wise comparative temporal analysis between Kriging generated data and observed data on the following basis:

a. Yearly

b. Monthly

c. Seasonal

\section{Literature review}

Geostatistics: By its introductory definition, Geostatistics offers a way of describing the spatial continuity of natural phenomena

*Corresponding author: Nazia Hassan Choudhury, Department of Water Resources Engineering, Bangladesh University of Engineering and Technology, Dhaka-1000, Bangladesh, Tel: 88-02-9665631; E-mail: kainazia24@gmail.com

Received October 01, 2015; Accepted November 23, 2015; Published November 30, 2015

Citation: Choudhury NH, Rahman A, Ferdousi S (2015) Kriging Infill of Missing Data and Temporal Analysis of Rainfall in North Central Region of Bangladesh. J Climatol Weather Forecasting 3: 141. doi:10.4172/2332-2594.1000141

Copyright: ( 2015 Choudhury NH, et al. This is an open-access article distributed under the terms of the Creative Commons Attribution License, which permits unrestricted use, distribution, and reproduction in any medium, provided the original author and source are credited. 
and provides adaptations of classical regression techniques to take advantage of this continuity [6].

Geostatistics is the result of introducing spatial dependence into statistical basics. Disregarding spatial dependence can invalidate methods for analyzing cross-sectional and panel data [7]. It was also established along with the already common statistical analysis of the variables, there must be an assessment of how well the models describe the spatial features of the data [8].

\section{Geostatistical kriging approach}

Kriging is a geostatistical method wherein a variable of interest $\mathrm{Z}(\mathbf{s})$ is decomposed into a deterministic trend $\mu(\mathbf{s})$ and a random, auto correlated errors form, $\varepsilon(\mathbf{s})$.

$$
z(s)=\mu(s)+\varepsilon(s)
$$

The symbol s simply indicates the location; it contains the spatial $\mathrm{x}^{-}$(longitude) and $\mathrm{y}^{-}$(latitude) coordinates. Deterministic trends are essentially results of math techniques based on the concept that future behavior can be predicted precisely from the past behavior of a set of data. These techniques ignore the existence of disturbances or external 'shocks' that may alter the data's future pattern. In geostatistics, the information on spatial locations allows the computation of distance between observations and thus model autocorrelation as a function of distance.

Geostatistical approach is applicable and methods are optimal when data are:

- normally distributed

- stationary (mean and variance do not vary significantly in space)

The different Kriging methods vary in degrees of complexity and in their underlying assumptions. Ordinary Kriging is one of the simplest forms of Kriging. It assumes that the data points demonstrate local stationarity, i.e., they contain no significant trends over the reasonably homogeneous smaller regions designated by the interpolation search neighborhood. As a result, it is a fairly accepted belief that moderate trends in the data do not significantly affect ordinary Kriging interpolations [9].

\section{Studies on kriging}

The pioneer study on Kriging [6] was conducted by Isaaks and Srivastava, 1989. Their book Applied Geostatistics is the introductory text wherein they explain how various forms of the estimation method called Kriging can be employed for specific problems. The book highlights an instructive case study of a simulated deposit.

A recent study performs evaluation of 17 infilling methods [10] including Kriging for time series of daily precipitation and temperature. Results revealed Kriging, among other stochastic methods, performs better infill than the set of deterministic methods. The linear regression residuals between precipitation and elevation incorporated into an ordinary Kriging model gave the best results. Use of elevation in stochastic methods to produce better results in the interpolation of climate variables has been highly recommended.

A case study was conducted on four forms of Kriging [11] and three forms of thin plate splines to predict monthly maximum temperature and monthly mean precipitation in Jalisco State of Mexico. Results show that techniques using elevation as additional information improve the prediction results considerably. From these techniques, trivariate regression-kriging and trivariate thin plate splines performed best.

\section{Study Area}

The study area is composed of the 4 districts Dhaka, Narayanganj, Narshingdi and Gazipur and falls within the North Central Region of Bangladesh as defined by FAP, 1989. The districts span over latitudes of $24.008^{\circ}$ to $24.028^{\circ}$ and longitudes of $90.006^{\circ}$ to $90.989^{\circ}$. A map is illustrated in Figure 1.

\section{Status quo of study area}

In these regions, flooding due to rainfall is pronounced and drainage congestion is becoming increasingly uncontrollable [12]. Drainage congestion occurs due to inadequacy of drainage system, heavy rainfall, high water level of peripheral rivers, unplanned development and encroachment. Numerous khals which fed water retention areas are being continuously filled up by new settlements, low-lands and paddy fields are readily converted into build-up areas by the housing estates and natural depressions and wetlands have been filled by solid wastes to reduce the filling costs in many parts. Unplanned urban development sprawls in the area and rivers are subjected to increasing encroachments as a bi-product of development. Water bodies in such settlements are fatally polluted if not filled up already.

BWDB maintains 7 well dispersed climate stations within the study area as per the distribution given in Table 1.

\section{Methodology}

\section{Data collection}

The station locations and corresponding available data is depicted in Table 2.

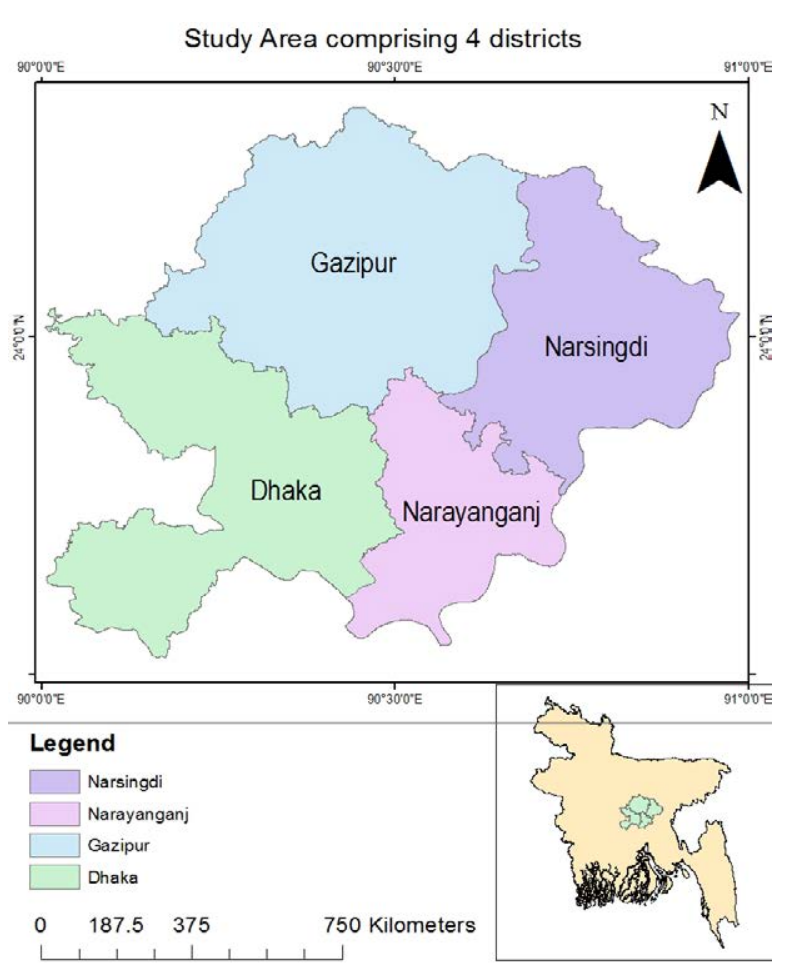

Figure 1: Study area comprising of 4 districts. 
Citation: Choudhury NH, Rahman A, Ferdousi S (2015) Kriging Infill of Missing Data and Temporal Analysis of Rainfall in North Central Region of Bangladesh. J Climatol Weather Forecasting 3: 141. doi:10.4172/2332-2594.1000141

Page 3 of 5

\begin{tabular}{|c|c|c|}
\hline District & Number of Stations & Station Name \\
\hline Dhaka & 3 & Banani, Savar, Dhaka_PBO \\
\hline Narayanganj & 1 & Shimrail \\
\hline Narsingdi & 1 & Narsingdi \\
\hline Gazipur & 2 & Joydebpur, Maona \\
\hline
\end{tabular}

Table 1: District wise distribution of climate stations.

\begin{tabular}{|c|c|c|c|c|c|c|c|}
\hline $\begin{array}{c}\text { Station } \\
\text { Name }\end{array}$ & $\begin{array}{c}\text { Station } \\
\text { ID }\end{array}$ & District & Latitude & Longitude & $\begin{array}{c}\text { Available } \\
\text { Data }\end{array}$ & $\begin{array}{c}\text { No. of } \\
\text { Years }\end{array}$ & $\begin{array}{c}\text { Percentage } \\
\text { of missing } \\
\text { data }\end{array}$ \\
\hline Shimrail & CL519 & Narayanganj & 23.64 & 90.62 & $1984-2013$ & 30 & 2.53 \\
\hline Narsingdi & CL76 & Narsingdi & 23.94 & 90.75 & $1984-2013$ & 30 & 17.19 \\
\hline Banani & CL42 & Dhaka & 23.8 & 90.4 & $1993-2013$ & 21 & 5.91 \\
\hline Savar & CL31 & Dhaka & 23.83 & 90.26 & $1984-2013$ & 30 & 12.35 \\
\hline Joydebpur & CL17 & Gazipur & 24.01 & 90.42 & $1996-2013$ & 18 & 15.91 \\
\hline $\begin{array}{c}\text { Dhaka_ } \\
\text { PBO }\end{array}$ & CL9 & Dhaka & 23.7 & 90.48 & $1984-2013$ & 30 & 6.85 \\
\hline Maona & CL43 & Gazipur & 24.15 & 90.4 & $1996-2013$ & 18 & 3.09 \\
\hline
\end{tabular}

Table 2: Stations Locations and Available Data.

\section{Data processing}

The amount of missing data each station contributes to the total missing volume of $7.95 \%$ which is generated by Kriging. Within the missing volume, Joydebpur constitutes the largest volume of missing data at $27 \%$ and Dhaka_PBO constitutes the smallest at $4 \%$. Kriging is executed via Arc-GIS 10.1 for each missing day individually with Ordinary Kriging and Prediction Type Surface via the Geostatistical Wizard. The results obtained from data generation of April, May and August for Joydebpur station in 2013 are depicted in Figures 2 and 3.

\section{Temporal analysis}

Firstly, for each year in each station calculations for both sets of data are executed to obtain:

- Total Annual Rainfall (TAR).

- Average Daily Rainfall(ADR).

- Total no. of wet days, Total no. of dry days.

- Maximum Daily Rainfall.

- Total Rainfall for each season and each month.

Secondly, for each station the Average Annual Rainfall (AAR) and finally, for all stations, values of AAR, maximum daily rainfall and seasonal rainfall distribution calculations are executed.

\section{Data Analysis, Results and Discussions}

\section{Data analysis}

Kriging assessment for the reference year 1999 is conducted for Joydebpur station and the months May from pre-monsoon season, August from monsoon season and October from post monsoon season. The generated Kriging data is then compared to actual observed data to reveal appreciable results via similar values and distribution.

\section{Results}

The Temporal Analysis results of Maona station are depicted in Figures 4 and 5. The station-wise results are tabulated in Table 3. The trends observed for TAR, ADR, number of wet days, number of dry days and maximum daily rainfall, the appreciable Kriging years observed per season and highest rainfall month for each station is shown.
For all stations, AAR, maximum daily rainfall and seasonal rainfall distribution results are depicted in graphs of (Figures 6-8) respectively.

\section{Discussions}

Kriging results are observed to be non-appreciable for post monsoon while it is significant and appreciably deviant from observed data for monsoon and pre-monsoon. The results are observed to be most effective for moderate rainfall values. Kriging for monsoon is also useful for the purpose of obtaining and studying expected moderate values although it is liable to uncertainties due to characteristic dynamism of Bangladesh's monsoon.

Kriging results are seen to be appreciably deviant from observed data for all stations and mildly for Dhaka_PBO. It is seen to be most effective for Joydebpur which had the highest amount of missing data.

However, anomalies and limitations exist. No results were obtained regardless of moderate observed rainfalls for May 2013 at Shimrail. The only observed values were at Maona and in spite of two fold Kriging, no
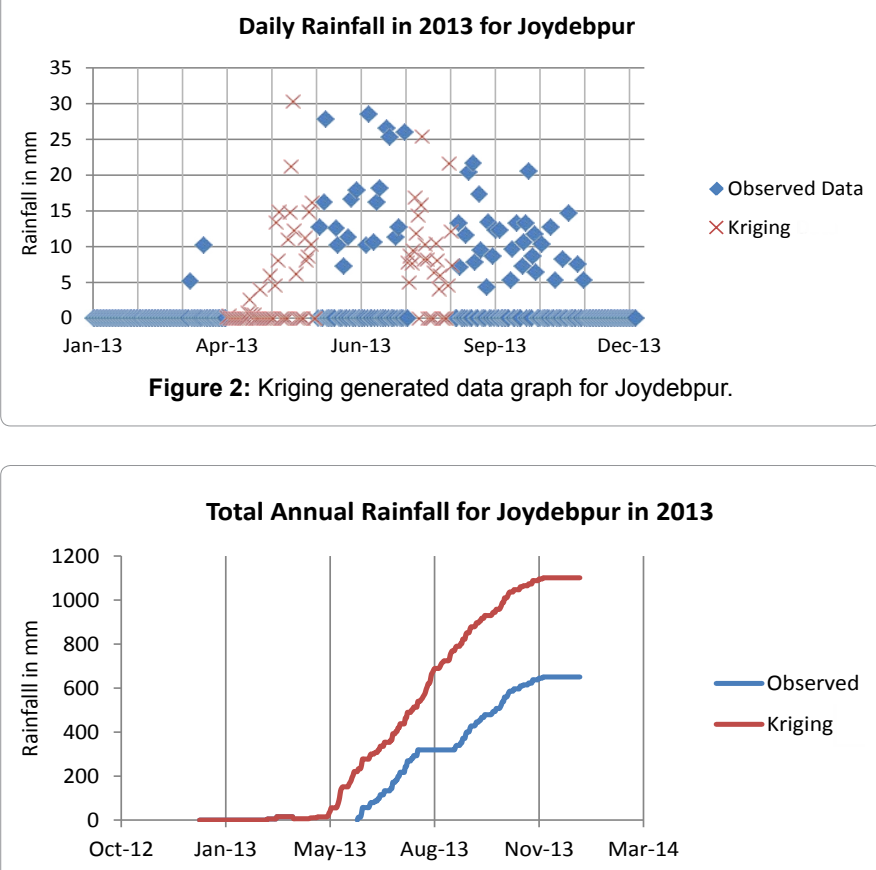

Figure 3: Total Annual Rainfall for 2 sets of data for Joydebpur in 2013.

\section{Total Seasonal Rainfall at Maona for 1996-2013}

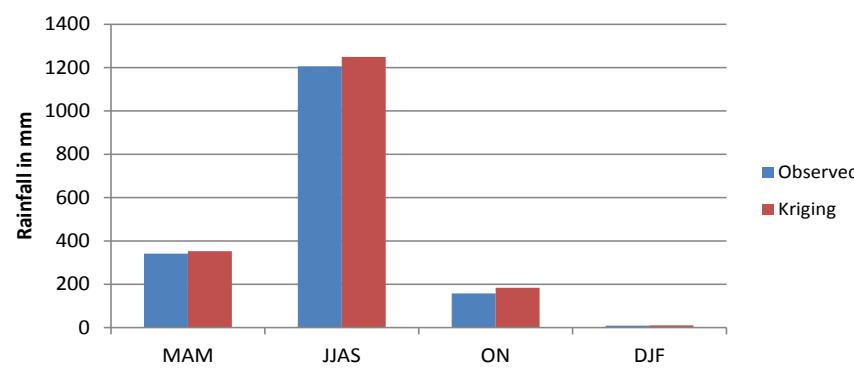

Figure 4: Total Seasonal Rainfall for Maona (1996-2013). 
Total Montly Rainfall at Maona for 19962013

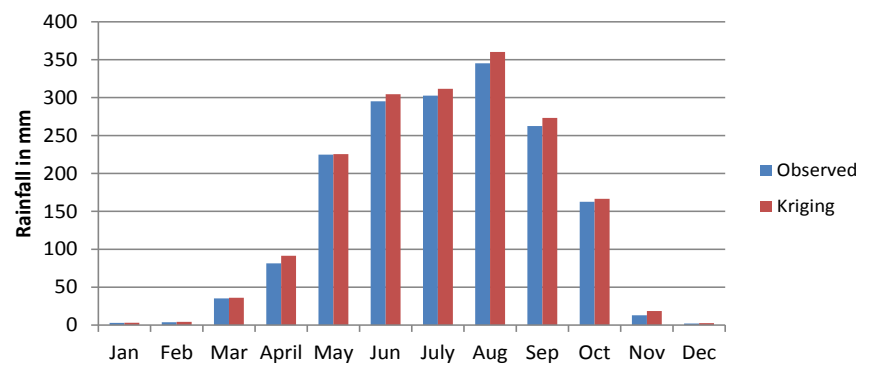

Figure 5: Total Monthly Rainfall for Maona (1996-2013).

generation was possible. Furthermore, missing data can be calculated only for days which have observed rainfall in another location. For low rainfall values, this may not necessarily mean rain in the station of interest.

\section{Trend interpretations}

The number of wet days is increased in any year due to Kriging but the overall trend over the years is observed to be same for both Kriging and observed data.

As depicted in results by trend lines, there is a localized effect in number of wet days and in number of dry days over the years. This can be cited as a result of global warming and as a sign of Bangladesh's North Central Zone's vulnerability to the phenomena. This further confirms the impacts of global warming to be continuously effective over the study area.

\section{Conclusions}

The assessment of Kriging reveals it to be a suitable method for infilling missing rainfall data and successful data processing for stations with missing data. Minimum errors and appreciable values are obtained for a missing station from moderate values of nearby observed rainfall. The values generated only for the highest or lowest observed rainfall values depict errors and deviant results. Most significant results are obtained for pre-monsoon and monsoon seasons; the volume of expected rainfall in these seasons can be deduced using Kriging. Kriging for post-monsoon has no or negligibly appreciable effect. Kriging in winter is redundant and can be anomalous. The number of wet days is increased in any year due to Kriging but the overall trend over the years is observed to be same for both Kriging and observed data. Maximum daily rainfall is unaffected by Kriging infill for all stations except Joydebpur when the observed value of $83.7 \mathrm{~mm}$ is generated to be $104.12 \mathrm{~mm}$.

The limitation lies in the fact that missing data can be calculated only for days which have observed rainfall in at least one other location. For low rainfall values, this may not necessarily mean rain in the station of interest. Applications of Kriging can be resourceful in studying the rainfall over ungauged vulnerable areas, locations of importance and likes. Kriging for monsoon is also useful for the purpose of obtaining and studying expected moderate values although it is liable to uncertainties due to characteristic dynamism of Bangladesh's monsoon.

The temporal analysis firstly as per station spanning over corresponding available years of data, for both Kriging and observed data illustrates total seasonal rainfalls and total monthly rainfalls to follow a normal distribution trend with Monsoon season giving the peaks; July is the rainiest month for all stations except Maona wherein August is both observed and Kriging generated as the rainiest month. Trend line visualizations used in all graph plots of number of wet days, number of dry days and daily maximum rainfall show increasing or decreasing trends. There is a localized effect in number of wet days and in number of dry days over the years. The number of wet days is decreasing at 5 stations (Dhaka_PBO, Joydebpur, Savar, Narsingdi and Shimrail) and increasing at 2 stations (Banani and Maona). The number of dry days follows no trend at 2 stations (Dhaka_PBO and Savar) and is increasing for 5 stations (Joydebpur, Narsingdi, Shimrail, Banani and Maona). This can be cited as a result of global warming and as a sign of Bangladesh's North Central Zone's vulnerability to the phenomena. This further confirms the impacts of global warming to be continuously effective over the study area. Localized changes in maximum daily rainfall are observed as it is decreasing for 4 stations (Joydebpur, Savar, Narsingdi and Shimrail) but increasing for 3 stations (Dhaka_PBO, Banani and Maona).

The temporal analysis secondly for all stations combined, deduced values of average annual rainfall, maximum daily rainfall and seasonal rainfall distribution. The average annual rainfall values are highest and lowest at Dhaka_PBO and Joydebpur respectively for both observed dataset and Kriging dataset; the highest average annual rainfall values are observed to be $2034 \mathrm{~mm}$ and generated by Kriging to be $2047 \mathrm{~mm}$.; the lowest average annual rainfall values are observed to be $1083 \mathrm{~mm}$ and generated to be $1322 \mathrm{~mm}$. The highest value of observed maximum daily rainfall is $448 \mathrm{~mm}$ in 2009 at Banani and lowest of $158.2 \mathrm{~mm}$ in 1996 at Joydebpur. From seasonal distributions at all stations,

\begin{tabular}{|c|c|c|c|c|c|c|c|c|}
\hline Station Name & $\begin{array}{c}\text { Month of } \\
\text { highest rainfall }\end{array}$ & Post-monsoon & Monsoon & Pre-monsoon & $\begin{array}{c}\text { Maximum Daily } \\
\text { Rainfall }\end{array}$ & No. of Dry days & No. of Wet days & TAR, ADR \\
\hline Dhaka_PBO & July & Nil & 1998 & 1996 & Increasing & No trend & Decreasing & Decreasing \\
\hline Joydebpur & July & 2004,2005 & $\begin{array}{c}1997,2002-2005 \\
2012,2013\end{array}$ & $\begin{array}{c}1996,1997,2002 \\
2003,20012 \\
2013\end{array}$ & Decreasing & Increasing & Decreasing & Decreasing \\
\hline Savar & July & 1993 & $\begin{array}{c}1993,1997 \\
2005,2009,2013\end{array}$ & 1997 & Decreasing & No trend & Decreasing & Decreasing \\
\hline Banani & July & 2002 & 2013 & 2004,2013 & Increasing & Increasing & Increasing & $\begin{array}{c}\text { Slightly } \\
\text { Decreasing }\end{array}$ \\
\hline Maona & Aug & $\begin{array}{c}1996,2002 \\
20013\end{array}$ & $2007,2010-2013$ & $\begin{array}{c}1996,1997 \\
2003,2013\end{array}$ & Increasing & Increasing & Increasing & Increasing \\
\hline Narsingdi & July & Nil & 1997, 2003, 2013 & $\begin{array}{c}1997,2003 \\
2004,2006,2013\end{array}$ & Decreasing & Increasing & Decreasing & $\begin{array}{l}\text { Significantly } \\
\text { Decreasing }\end{array}$ \\
\hline Shimrail & July & 2002 & 2002 & 2005,2007 & Decreasing & Increasing & Decreasing & $\begin{array}{l}\text { Significantly } \\
\text { Decreasing }\end{array}$ \\
\hline
\end{tabular}

Table 3: Summary of station-wise results. 
Citation: Choudhury NH, Rahman A, Ferdousi S (2015) Kriging Infill of Missing Data and Temporal Analysis of Rainfall in North Central Region of Bangladesh. J Climatol Weather Forecasting 3: 141. doi:10.4172/2332-2594.1000141

Page 5 of 5

\section{AAR of Stations}

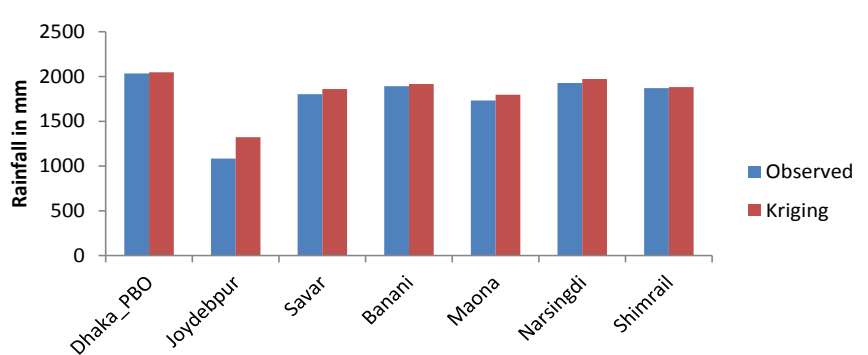

Figure 6: AAR for all stations.

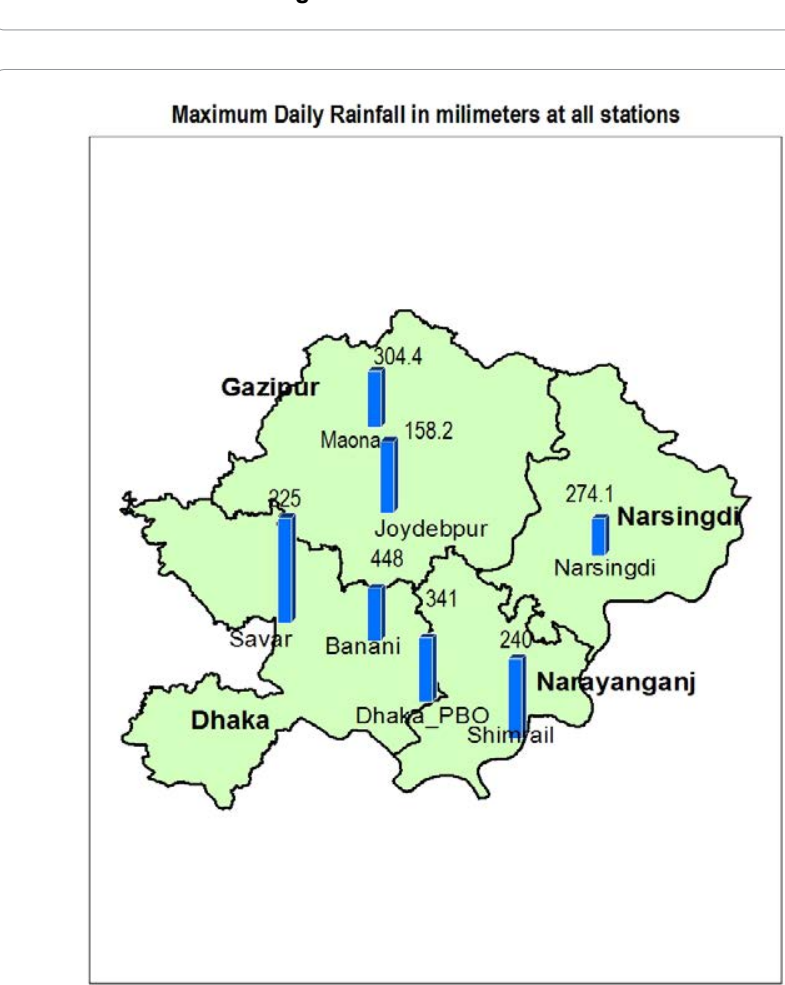

Figure 7: Observed Maximum Daily Rainfall for all Stations (1984-2013).

\section{Seasonal Rainfall Distribution in each} station

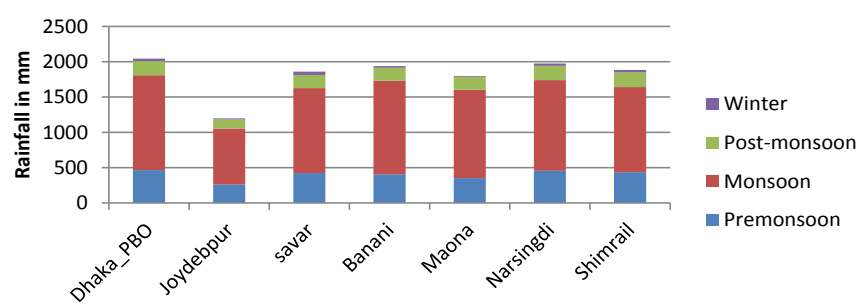

Figure 8: Seasonal Rainfall Distribution in all stations.

Citation: Choudhury NH, Rahman A, Ferdousi S (2015) Kriging Infill of Missing Data and Temporal Analysis of Rainfall in North Central Region of Bangladesh. J Climatol Weather Forecasting 3: 141. doi:10.4172/2332-2594.1000141 developed from completed set of Kriging generated data, it is indicative that the monsoon season contributes highest rainfall at all stations, followed by pre-monsoon, post-monsoon and winter respectively; the highest monsoon rainfall of $1343 \mathrm{~mm}$ is at Maona, the highest premonsoon rainfall of $465 \mathrm{~mm}$ is at Dhaka_PBO and the highest postmonsoon rainfall of $208 \mathrm{~mm}$ is at Shimrail.

\section{References}

1. Matsumoto $\mathrm{J}$ (1988) Synoptic features of heavy monsoon rainfall in 1987 related to the severe floods in Bangladesh. Bulletin of the Department of Geography, University of Tokyo 20: 43-56.

2. Hasan GMJ, Alam R, Islam QN, Hossain S (2012) Frequency Structure of Major Rainfall events in the North-Eastern part of Bangladesh. Journal of Engineering Science and Technology 7: 690-700.

3. Schimidli J, Frei C (2005) Trends of heavy precipitation and wet and dry spells in Switzerland during $20^{\text {th }}$ century. International Journal of Climatology 25: 753 771 .

4. Brifa KR, Van der Schrier G, Jones PD (2009) Wet and dry summers in Europe since 1750: evidence of increasing drought. International Journal of Climatology 29: 1894-1905

5. Zhang Q, Xu CY, Zhang Z (2009) Observed changes of drought/wetness episodes in the Pearl River Basin, China, using the standardized precipitation index and aridity index. Theoretical and Applied Climatology 98: 89-99.

6. Isaaks EH, Srivastava, Mohan R (1989) An Introduction to Applied Geostatistics. Oxford University Press, New York 561.

7. Robinson PM (2008) Developments in the analysis of spatial data. Journal of the Japanese Society of Computational Statistics 38: 87-96.

8. Haining R (1990) Spatial Data Analysis in the Social and Environmenta Sciences, Cambridge University Press, Cambridge 111-112.

9. Deutsch, Clayton V, Journel AG (1992) GSLIB: Geostatistical Software Library and User's Guide. Oxford University Press, New York 340.

10. Campozano L, Sanchez E, Aviles A, Samaniego E (2014) Evaluation of infilling methods for time series of daily precipitation and temperature: The case of Ecuadorian Andes. MASKANA 5: 99-115.

11. Boer EPJ, Beursa KM, Hartkamp AD (2001) Kriging and thin plate splines fo mapping climate variables. International Journal of Applied Earth Observation and Geoinformation 3: 146-154.

12. Ahmed T, Mirjahan M (2013) Rainfall runoff analysis of eastern Dhaka city using mathematical model. $4^{\text {th }}$ International Conference on Water and Flood Management 2: 113-121.
OMICS International: Publication Benefits \& Features

Unique features:

- Increased global visibility of articles through worldwide distribution and indexing

Showcasing recent research output in a timely and updated manner

- Special issues on the current trends of scientific research

Special features:

- 700 Open Access Journals

50,000 Editorial team

Rapid review proces

Quality and quick editorial, review and publication processing

Indexing at PubMed (partial), Scopus, EBSCO, Index Copernicus, Google Scholar etc.

Sharing Option: Social Networking Enabled

Authors, Reviewers and Editors rewarded with online Scientific Credits

Better discount for your subsequent articles

Submit your manuscript at: http://www.omicsonline.org/submission/ 